\title{
Design of Agent-Based Agricultural Product Quality Control System
}

\author{
Yeping Zhu, Shijuan Li, Shengping Liu, and E. Yue \\ Laboratory of Digital Agricultural Early-warning Technology of Ministry of \\ Agriculture of China, Institute of Agricultural Information, CAAS, \\ 100081 Beijing, China \\ \{zhuyp, lishijuan.spliu, eyue\} @mail.caas.net.cn
}

\begin{abstract}
Aiming at the problems existed in agricultural product quality control, management and traceability such as the considerable influence of human factors, weak ability of handling emergencies and lacking of support of intelligent key technologies, this study explores the application of agent theory, method and technique to solve the problems of process control, traceability, intelligent information watching and information technology application to emergency reaction conditioned on the general characteristics from production to circulation. In this study agent application and development method will be put forward. By means of investigating its communication and cooperative mechanism, we design the agent-based universal system framework for quality control of agricultural product. According to production and processing characteristics of different agricultural products, corresponding controlling unit and condition are increased to adapt to the special aim.
\end{abstract}

Keywords: Agent, Agricultural product, Quality control.

\section{Introduction}

As the important problem which concerns the masses most, food safety affects people's health and life, involves the economic healthy development and social stabilization. How to control and manage food safety effectively has been becoming a research focus in recent years. The watching and effective management to product flow of farm produce can not only settle the problems of quality control and information delivery existed in every link such as production, processing, transportation, storage and sales, but also protect native agricultural product market and food safety. Europe began quality monitor and control in stockbreeding long ago. After the study and evolvement year by year, now relative perfect system has been come into being [1-3]. Since 21 st century china gradually strengthened the study on food safety control method and system. A series of relative standards and guides have been established. Zheng Fengtian and Zhang Yongjian et al proposed that china must set up food safety system [4, 5]. Ye Yongmao considered the compellent food safety standard system should be constituted by means of reforming food safety management and operational mechanism and enhancing food safety legislation [6]. 
The author ever studied bee production quality traceability and developed software system [7, 8 9]. In the process of agricultural product quality control and traceability, man-made factors play an important role. Being lack of intelligent key technologies, although some technologies such as sensor, radio frequency identification and image recognition had been adopted in information collecting [10-15], database management, query and analysis still are the main method in agricultural product quality control. So there are no enough technologies involved in quality control to reply emergency. The difficulties existed in information collection, tracking and control for the small agricultural product, which need to be blended such as foodstuff and bee production, demand the corresponding information technologies as support to settle the key issues and reduce the effect of man-made factors. In this paper a method to control agricultural product quality with the characteristics of perceptivity, intelligence and cooperation will be studied. It provides technology support and universal resolution for control and traceability of such agricultural products as grain, bee product, vegetable and fruit etc., which are small, distinctly characteristic of dispersive production and need to be combined processed.

\section{Status and Analysis of the Study}

The concept of agent was promoted in the end of 1970s, and the study of its methods and implementations has been developed in an active period. As one research domain of the distributed artificial intelligence, agent theory and technology have aroused a great deal of attention because multi-agent system (MAS) plays an important role in modern computer science and its application. In a multi-agent system any agent needs to communicate and cooperate with the other agents. Its behavior and decision vary with the other agents and conversation rules. The universal language-behavior theory formal language is used to make the agents in communication understand their respective inner state and purpose [16-25].

The application of MAS technology in agriculture is less than that in other fields. Liu Huimin at Capital Normal University studied multiple collaborative approaches based on the analysis of MAS technologies and theories, promoted an implementation plan for the MAS coordination mechanism based on Web Services technology to provide effective method and implementation technology [26]. Through the analysis on agricultural expert system and its characteristics, Yang Yan put forward the design project of web-based agricultural expert system. Xue Ling at Peking University and Chinese Academy of Agricultural Sciences applied agent to the study on modern agricultural economic management and decision-making system, provided the structure and components of Agriculture Economy Intelligent Decision Support System (AEIDSS), analyzed the implementation method of classifier-based agent, and discussed the work principle of dynamic analysis, evaluation, forecasting and optimization under multi-agent communication and cooperative environment. The author also designed the Agent-based Cooperative Analysis and Decision Support System for Regional Agricultural Economic Information [27-30]. 
With the issue of "Food Safety Law" in 2009, china governments and departments all levels increased the construction of agricultural standard system and the control power of agricultural product market, and a multitude of production bases for high quality agricultural products have come into service [31-37]. China, as a large country for production area and yield, not only is a production country for agricultural products, but also is a consumption country. So how to make the best of existing agricultural information network and comparative advanced technologies to provide information service of agricultural products quality, safety, standard and trademark etc. in order to boost the information construction and control method study of agricultural products quality safety is important and impendent. Building agricultural products traceability system is an inevitable trend for world agriculture, and traceability system has been becoming an important development direction.

No study directly concerns the agent application on agricultural products quality safety and control except only a few reports about key technology and quality inspection method. Dmytro Tykhonov et al described a kind of multi-agent imitation model for trust tracking game. Trust tracking game simulated the game player, was a research measure to collect the human behavior data in the food supply chain with the characteristics of asymmetry food quality and safety information [38]. Dr Eleni Mangina and Ioannis Giavasis provided a multi-agent system to supervise gellan gum production, which included online data collection, forecasting the future benefit by capturing historical data automaticly [39]. Moises Resende-Filho mentioned a sort of commission surrogacy model to encourage food safety tracking system. His study indicated the more reliable tracking system make the dealer attach more importance to food safety; the inapposite tracking system couldn't inspirit the dealer to use the safe material in food industry [40]. Zhu Li and Wang Haiyan used the theory and principle of HACCP to discuss how to build food safety quality control system in food supply chain of Chain Supermarket [41]. Deng Ning et al tried to apply the core concept of agent on supply train risk control system, and proposed the framework mode to effective manage supply chain risk [42]; From the angle of quality guarantee Xiao Yuan and Liang Gongqian analyzed the conflicts among enterprises in supply chain, put forward the quality supervision mechanism. Multi-agent technology was applied to modeling for quality supervision system, and the system structure was provided [43]. Li Feng studied how to collect economically the real-time information of transporting goods and send to the back-end server (logistics information system). Radio Frequency Identification (RFID) was used by mobile front end subsystem to retrieve information of goods in automatic fashion, and the corresponding agents fulfilled the data processing and delivery. Back-end server also was built on mobile agent. This can not only ensure the customization of information collection, but also increase the system opening [44].

The increased demand on innovating food safety and quality control method offers a chance for agent technology with characteristics of sociality, autonomy, intelligence and mobility. MAS technology provides a method and measure for collaboration integration to guarantee quality, offers a feasible scheme for running quality supervision system successfully. Appling agent technology to study agricultural product quality safety and control method has far-reaching meaning on food safety and citizen health, at the same time will provide a new research method. 


\section{Design of Agent-Based Agricultural Product Quality Control System}

First of all, let's analyze the traditional flow of production, processing, sales, quality tracking and traceability for agricultural product (Fig. 1). In quality traceability database is the kernel technology.

Figure 2 shows agent-based agricultural product quality control flow which core is the agent cooperation and intelligent control.

The information delivery, task assignment and cooperation in whole system are on the control of information management agent and task management agent.

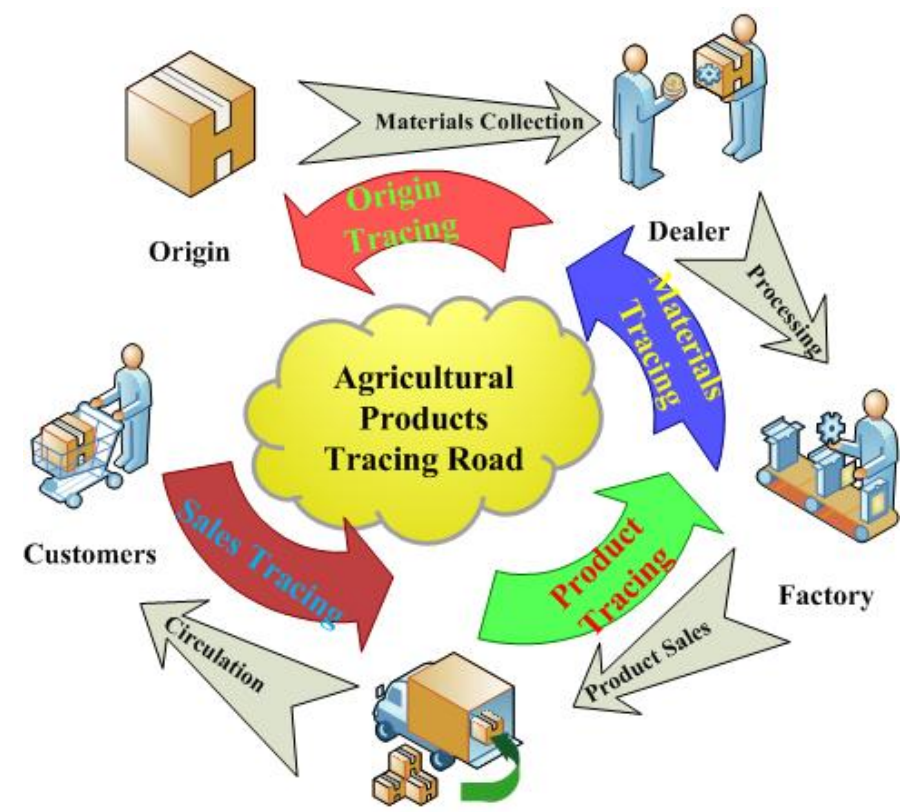

Vendors

Fig. 1. Traditional flow from production to sales of agricultural product and quality traceability

Agent-based agricultural product quality traceability ensures the quality control from the source of supply chain. Production information agent, purchase information agent, processing information agent, sales information agent, circulation information agent guarantee the communication with each node on supply chain and the responsiveness and veracity of information collected. System will feed back the corresponding behavior to task management agent according to traceability demand. Task management agent communicates with each agent concerned and delivers the results to consumer. Agent-based agricultural product quality traceability and control is 
bestowed with unique advantages. It can realize the real-time information collection and intelligent processing, make purchase, dealer and enterprise obtain the product and industry information so as to adjust their management, offer related traceability information to the consumer.

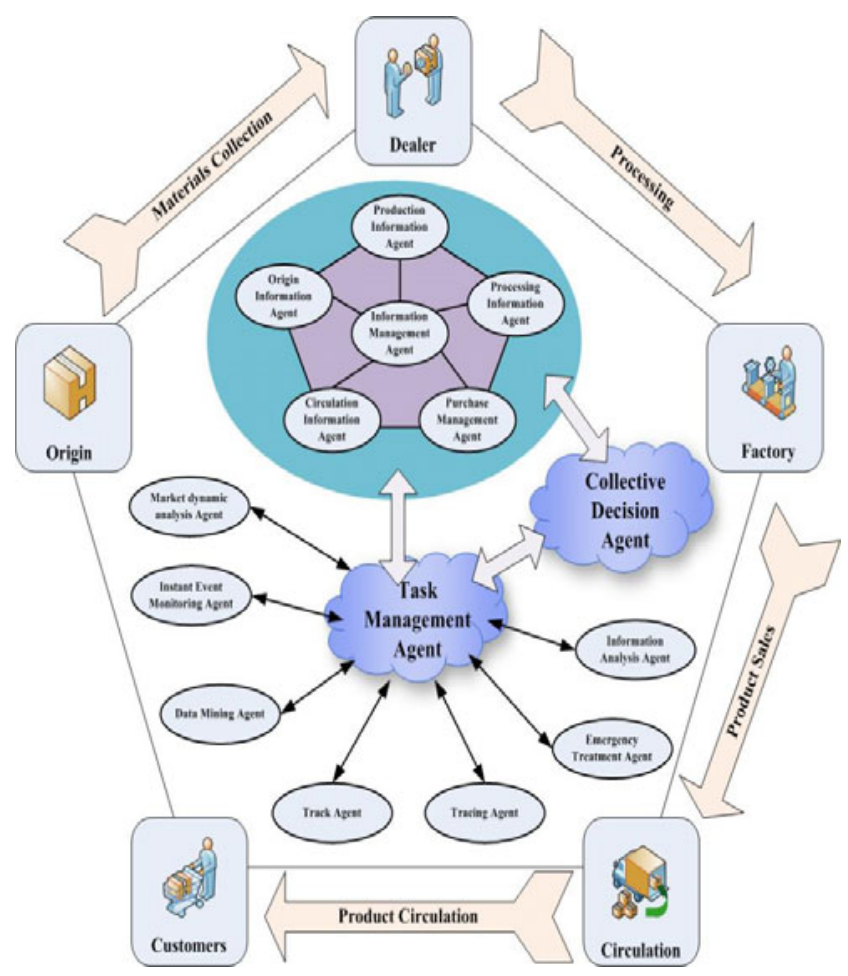

Fig. 2. Agent-based agricultural product quality control flow

\subsection{System Architecture}

The multi-agent system to control agricultural product quality through the whole course includes several agents such as information management agent, task management agent, tracing and traceability agent, market analysis and forecast agent, logistics management agent, instant event monitoring agent, emergency treatment agent and data mining agent and so on.

System architecture is based on multi-agent management platform. Agentoriented thinking mode and cooperative evolvement theory replace the traditional structural design and object oriented design methods. System is composed of five parts i. e. user, communication and task sales, task resolving, information management and basic information (Fig. 3). Each part includes many agents which do their own work. 


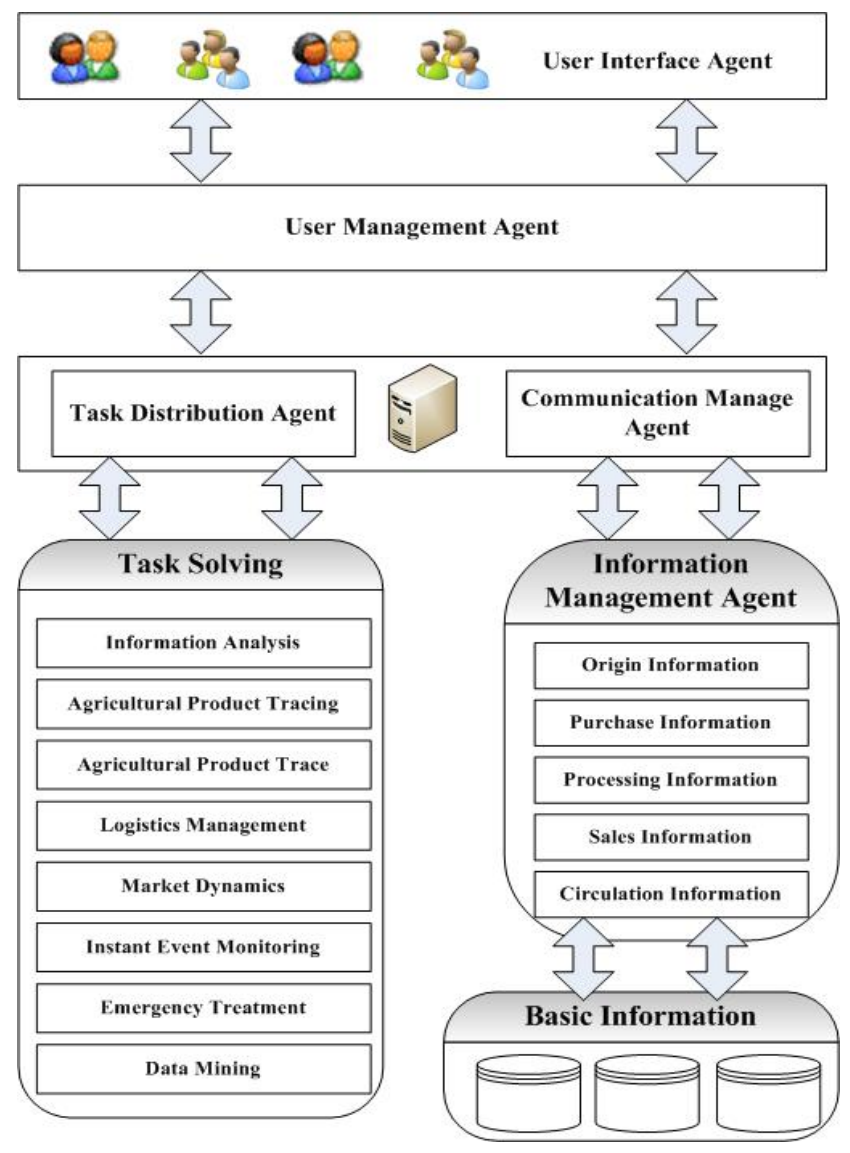

Fig. 3. Architecture of agent-based agricultural product quality control system

\subsection{Function Design of System}

User management agent. Interface agent accepts the task requests from users and delivers to task management agent. The results from multi-agent system are sent back to interface agent through task management agent. User interface agent creates different interface including drawing, table, text and figure depending on the different tasks.

Information management agent. Information management agent is responsible for collecting and managing the information from production to sales for example information modification, storage and delivery.

Task management agent. After receiving the requests from users, task management agent assigns distinct tasks to different agents for instance information analysis, production information collection task, tracing and traceability, logistics management, market analysis, instant event monitoring, emergency treatment. These agents fulfill 
the information collection, analysis and time arrangement in agricultural production. For example, when emergency takes place, task management agent will call emergency treatment agent which gives reaction and information prompt and makes assistant decision on emergency.

Task resolving agent. Task resolving agent consists of many agents. When user or other agent sends out task or cooperation requirement, task resolving agent searches and call the relevant agents, then submits task request. If the agent receiving task is idle, it will accept the task and begin to address the task. The results will be returned to task resolving agent by communication and task management agents.

These collaboration agents include:

Information analysis agent. Which makes out statistical analysis and creates various graphs and report forms.

Agricultural product tracing agent. It is responsible for the information collection, filtration, treatment, storage, earmark and bar code creation of the whole supply chain from production to processing to table.

Agricultural product traceability agent. Which searches for each tache of the whole supply chain aiming at the different demands of consumer, enterprise and government, for instance whether each tache accords with respective standards or not.

Market analysis and forecast agent. It analyses market information and comes into being market forecast with various methods. If there is a great discrepancy between the two forecast results, one result or several results will be provided to predict market dynamic by means of consultation, competition and ratiocination.

Logistics management agent. It administers the logistics information and dispatch.

Instant event monitoring agent. On the one hand, it deals with the information from interface; on the other hand, it supervises the abnormity with each sector on supply chain, analyzes whether an emergency occurs or not. If system thinks an abnormal event or emergency has taken place, the early-warning will be sent out and communication starts.

Emergency treatment agen. It classifies the emergency for example quality safety, quantity safety, abnormal fluctuation of market and so on. Then the corresponding agent will be called to analyze and search the response plan. If there is not response plan, system gives an alarm to ask for human intervention. Otherwise the response plan will be called to deal with the emergency. At the same time, system will give the assistant decision.

Data mining agent. It makes data mining and learning on the basis of collecting a large of information. It promotes the intelligence of agent, needs human intervention and certification.

\subsection{Communication Language and Standard between Agents}

In order to guarantee the veracious cooperation between agents we must standardize their communication manner. Communication of multi-agent has been built on the Agent Communication Language (ACL), and follows ACL standard of the Foundation for Intelligent Physical Agents. 
In cooperation process matching conditions include communication action, message parameter and parameter expression and so on. Every agent has special matching format and combination. Only the message instruction suiting the format completely can be recognized by target agent and implemented.

\subsection{Cooperation among Multi-agent System}

Cooperation embodies the sociality of agent, and is a main predominance of multiagent system. In agent-based agricultural product quality control system, we take certain unqualified product as example. After receiving task requirement, interface agent calls communication agent to deliver the task to task management agent. Task resolving agent analyses the massage from task management agent, then sends out news to data management agent in order. Data management agent looks up the data concerned and sends out to emergency treatment agent. Emergency treatment agent runs the relative models to create a suit of assistant decision scheme, and then calls the other agents to consult. Finally interface agent will receive the plan and data used, which maybe is an assistant decision scheme or a warn-earning message. Each agent can be activated at any moment. Many agents can realize consultation and competition.

\subsection{System Development and Application}

We chose Java language to develop system on Windows operation platform in order to guarantee the universality and transferability of multi-agent system.

Agents with various function were constructed by means of exploiting principal part and interating softwares. For the function modules such as collection, monitoring and analysis of bee product information, we made best use of former programme to encapsulate, transfer and build the corresponding function agent. The reuse and share of the research materials on our hand can save workload effectively. The functions such as decision-making and emergency response need the cooperation, consultation, communication and competition among agents to reach the practical results. Communication of multi-agent had been built on the TCP/IP protocol. The most popular agent communication language--KQML (Knowledge Query Manipulation Language) had been used to exchange messages among agents so the cooperation and collaboration decision-making was realized.

\section{Conclusion}

This study on agent-based agricultural product quality control method will provide elementary way and information technology tool for building quality control, supervision and traceability system as well as information platform, will reduce the amount of development work greatly, will increase the ability to answer for the quality safety problems, can offer a tool of information supervision, control and coopration for whole supply chain, will help to realize the digitilization and intelligent management for agricultural products.

Acknowledgments. This study was supported by the National Natural Science Foundation of China (Grant No. 60972154) and the National Science \& Technology Pillar Program (Grant No. 2009BADA9B02). 


\section{References}

1. Chen, S.-d., Song, D.-y.: The development and enlightenment of the quality traceability system of livestock in France and Netherlands. China State Farms 2, 37-41 (2007) (in Chinese)

2. Chen, H.-h., Tian, Z.-h.: Comparative Study on Traceability system of agricultural products at home and abroad. Market Modernization, 5-6 (2007) (in Chinese)

3. Regattieri, A., Gamberi, M., Manzini, R.: Traceability of food products: General framework and experimental evidence. Journal of Food Engineering 81, 347-356 (2007)

4. Zheng, F.-t.: The Adjustment from Food Security System to Food Safety System-The Strategic Transfer Faced by Chinese Food Production Systems. Journal of Finance and Economics 2, 71-75 (2003) (in Chinese)

5. Zhang, Y.-j., Liu, N., Yang J.-h.: Study on Building and Promoting the System of China's Food Security. China Industrial Economy 2, 14-20 (2005) (in Chinese)

6. Ye, Y.-m.: Thinking about the Establishment of China Food Safety Quality Control System. World Standardization and Quality Management 4, 4-6 (2002) (in Chinese)

7. Zhu, Y., Zhao, J., Liu, S., Yue, E.: Design of bee products quality monitoring information service platform. In: IFIP International Federation for Information Processing, Computer and Computing Technologies in Agriculture II, Beijing, pp. 2141-2149 (2008)

8. Li, S.J., Zhu, Y.P., Liu, S.P.: Status quo of quality safety of bee products and construction of traceability management information system 24, 293-297 (2008) (in Chinese)

9. Liu, S.P., Zhu, Y.P., Li, S.J.: Research on Data Acquisition System for Agent-based Bee Product Traceability Platform. In: IEEE Proceedings of the, International Conference on Computer and Computing Technology Applications in Agriculture (2009) (in Press)

10. Delicious Group Co., Ltd. Shandong.: Analysis of RFID technology in meat and food safety in the application of retrospective. China AUTO-ID, 1, 69-71 (2008) (in Chinese)

11. Wen, X.-y.: The Situation and Development of Food Traceability. Radio Frequency Identification Technologies and Applications 4, 12 (2006) (in Chinese)

12. Chen, J.-P.: China's agricultural products quality and safety of the status quo and recommendations. unpublished (in Chinese)

13. Liu, J.-h., Dou, Y.-p.: Application of Automatic Identification Technology in Quality Traceability. Computer Simulation 2, 225-227 (2005) (in Chinese)

14. Liu, Z.-z.: Application of RFID in Securing Food Supply Chain. Logistics Technology 6, 18-20 (2006) (in Chinese)

15. Zheng, D.-y., Wei, Q.-b., Feng, J.-y.: Implementation of Tracing and Tracking Safety Mechanism of Agricultural Product Packaging Based on RFID. Packing Engineering 27, 153-158 (2006) (in Chinese)

16. Giordano, R.: An intelligent agent for the groundwater pollution risk evaluation. In: Coastal Zone Management in the Mediterranean Region, Valenzano, Italy, pp. 47-56. CIHEAM-IAMB (2002)

17. Lima, R.M., Sousa, R.M., Martins, P.J.F.: Distributed production planning and control agent-based system. International Journal of Production Research 44, 3693-3709 (2006)

18. Patt, A., Siebenhüner, B.: Agent Based Modeling and Adaptation to Climate Change. Vierteljahrshefte zur Wirtschaftsforschung 74, 310-320 (2005)

19. Roche, C., Fitouri, S., Glardon, R., Pouly, M.: The Potential of Multi-Agent Systems in Virtual Manufacturing Enterprises. In: 9th International Workshop on Database and Expert Systems Applications, DEXA 1998 (1998)

20. Yang, G.-w., Du, Y.-f., Guo, L.: Research of Multi-Agent System. Computer Knowledge and Technology 4, 322-323 (2008) (in Chinese) 
21. Ying, L.: Studies of Agent-based Project Management Information System. Journal of East China University of Science and Technology, Social Science Edition 1, 61-64 (2007) (in Chinese)

22. Wang, N.-h., Wang, C.-1.: Application Research on Mobile Agent in Expert System of Forest Diseases and Pests. Forest Engineering 3, 10-13 (2008) (in Chinese)

23. Zhao, L.-d.: Execution and Evaluation Strategies of Multi-agent Diagnostic Task. Journal of Industrial Engineering and Engineering Management 2, 86-89 (2003) (in Chinese)

24. Zeng, Y.-c.: The Summary of Agent Technology Researching. Computer Knowledge and Technology 21, 525-527 (2008) (in Chinese)

25. Quan, L.-n., Fan, L.-p.: Agent Technology Application on Water Quality Decision Support System. Machinery \& Electronics 5, 77-79 (2006) (in Chinese)

26. Liu, H., Wang, H., Wang, W.S.: Study about MAS-based Agricultural Expert System Platform. Microcomputer Development 13, 8-10 (2003) (in Chinese)

27. Zhu, Y.P., Li, S.J., Liu, S.P., Xu, Y.C.: Agent-based cooperative analysis and decision support system for regional agricultural economic information. In: Arabnia, H.R., de la Fuente, D., Jose, A. (eds.) Proceedings of the 2009 International Conference on Artificial Intelligence, WORLDCOM 2009, vol. 1, pp. 96-99. CSREA Press, Olivas (2009)

28. Xue, L., Zhu, Y.P., Xue, Y.: Rearch on agriculture economy intelligent decision support system based on multi-agent system. System Sciences and Comprehensive Studies in Agriculture 20, 172-176 (2004) (in Chinese)

29. Zhu, Y.P., Li, S.J., Liu, S.P., Xu, Y.C.: Agent-based cooperative analysis and assistant decision-making method for regional agricultural economic information. In: Sixth International Conference on fuzzy Systems and Knowledge Discovery, vol. 7, pp. 317-321 (2009)

30. Liu, S.P., Zhu, Y.P.: Establishment of wheat simulation model based on agent technology. Journal of Anhui Agricultural Sciences 35, 6026-6028 (2007) (in Chinese)

31. Fan X.-f., Zhou D.-y.: Information traceability and food safety management of agricultural products. Commercial Times 12, 87-88 (2007) (in Chinese)

32. Wu, H.-j., Ni, W.-h.: Design of Traceability Architecture of Food Supply Chain. Industrial Engineering Journal 5, 45-65 (2008)

33. Zhang, W.-b., Gu, Z.-y.: Mechanism analysis on food safety based on management of food supply chain. Science and Technology of Food Industry 28, 215-220 (2007) (in Chinese)

34. Fang, Y., Gao, G., Fan, X., Chen, H.-n.: Research on China's food safety tracing system. Agricultural Quality and Standards 2, 37-39 (2005) (in Chinese)

35. Wang L.-f., Lu C.-h., Hu Y.-n., Xie J.-f., Bai H.-w., Bai Y.-f.: Design and implementation of a novel swine tag and traceability system for swine and meat products. Agriculture Network Information, 17, 25-27 (2006) (in Chinese)

36. National Bureau of Statistics Of China.: 2008 National Economic and Social Development Statistical Communique (2008) (in Chinese)

37. Wu, D., Lu, C.-Y., Chen, H.: Food quality and safety traceability system research progress and application prospect in the tea industry. Chinese Agricultural Science Bulletin 1, 251255 (2009) (in Chinese)

38. Tykhonov, D., Jonker, C., Meijer, S., Verwaart, T.: Agent-Based Simulation of the Trust and Tracing Game for Supply Chains and Networks. Journal of Artificial Societies and Social Simulation 11(3, 1) (2008)

39. Mangina, E., Giavasis, I.: The theoretical framework of agent based monitoring for use in the production of gellan gum in a microbial fermentation system. International Journal of Computer Science \& Applications, Techno-mathematics Research Foundation 2, 38-48 (2005) 
40. Moises, R.-F.: A Principal-Agent Model for Investigating Traceability Systems Incentives on Food Safety. In: 105th EAAE Seminar, International Marketing and International Trade of Quality Food Products, pp. 127-138 (2007)

41. Zhu, L., Wang, H.-y.: Research on Quality Control System of Food Supply Based on Chain Supermarket. Logistics Technology 10, 206-208 (2005) (in Chinese )

42. Deng, N., Liu, J.s., Luo, R.-s.: Agent- based Research on Supply Chain Risk Management. Chinese Journal of Management Science 10, 412-416 (2006) (in Chinese)

43. Xiao, Y., Liang, G.-q.: Quality supervise mechanism of supply chain model base on MultiAgent system. Modern Manufacturing Engineering 2, 26-28 (2007) (in Chinese)

44. Li, F.: Goods Tracing System Based on RFID and Agent Technology. Computer Engineering 34, 277-279 (2008) (in Chinese) 